\title{
Correction to: Correlation of CSF flow using phase-contrast MRI with ventriculomegaly and CSF opening pressure in mucopolysaccharidoses
}

\author{
Amauri Dalla Corte ${ }^{1,2^{*}}$ (D) Carolina F. M. de Souza ${ }^{2}$, Maurício Anés ${ }^{3}$, Fabio K. Maeda ${ }^{4}$, Armelle Lokossou ${ }^{5}$, \\ Leonardo M. Vedolin ${ }^{6}$, Maria Gabriela Longo ${ }^{7}$, Monica M. Ferreira ${ }^{8}$, Solanger G. P. Perrone ${ }^{2}$, Olivier Balédent ${ }^{5}$ \\ and Roberto Giugliani ${ }^{1,2}$
}

\section{Correction to: Fluids Barriers CNS (2017) 14:23 DOI 10.1186/s12987-017-0073-2}

After publication of the article [1], it has been brought to our attention that the full funding acknowledgement is missing from the original article. It should read as below.

\section{Acknowledgements}

We gratefully acknowledge the financial support provided by the Fundo de Incentivo à Pesquisa e Eventos of Hospital de Clínicas de Porto Alegre for the publication of the present study.

\section{Funding}

The publication fees were covered by the Fundo de Incentivo à Pesquisa e Eventos of Hospital de Clínicas de Porto Alegre.

\begin{abstract}
Author details
${ }^{1}$ Post-Graduate Program in Medical Sciences, Universidade Federal do Rio Grande do Sul, Porto Alegre, Brazil. ${ }^{2}$ Medical Genetics Service, Hospital de Clínicas de Porto Alegre, Rua Ramiro Barcelos 2350, Porto Alegre, RS 90035-903, Brazil. ${ }^{3}$ Medical Physics and Radioprotection Service, Hospital de Clínicas de Porto Alegre, Porto Alegre, Brazil. ${ }^{4}$ Clinical Engineering, Santa Casa de Misericórdia de Porto Alegre, Porto Alegre, Brazil. ${ }^{5}$ Image Processing Unit, Amiens University Hospital, Amiens, France. ${ }^{6}$ Department of Neuroradiology, DASA Group, São Paulo, Brazil. ${ }^{7}$ Department of Radiology, Massachusetts General Hospital, Boston, USA. ${ }^{8}$ Anesthesiology Service, Hospital de Clínicas de Porto Alegre, Porto Alegre, Brazil.
\end{abstract}

The online version of the original article can be found under doi:10.1186/s12987-017-0073-2.

\footnotetext{
*Correspondence: dalacorte@gmail.com

${ }^{2}$ Medical Genetics Service, Hospital de Clínicas de Porto Alegre, Rua

Ramiro Barcelos 2350, Porto Alegre, RS 90035-903, Brazil

Full list of author information is available at the end of the article
}

\section{Publisher's Note \\ Springer Nature remains neutral with regard to jurisdictional claims in pub- lished maps and institutional affiliations.}

Received: 4 October 2017 Accepted: 5 October 2017

Published online: 13 October 2017

\section{Reference}

1. Corte A, de Souza C, Anés M, Maeda F, Lokossou A, Vedolin L, et al. Correlation of CSF flow using phase-contrast MRI with ventriculomegaly and CSF opening pressure in mucopolysaccharidoses. Fluids Barriers CNS. 2017; 14:23. doi:10.1186/s12987-017-0073-2. provided you give appropriate credit to the original author(s) and the source, provide a link to the Creative Commons license, and indicate if changes were made. The Creative Commons Public Domain Dedication waiver (http://creativecommons.org/ publicdomain/zero/1.0/) applies to the data made available in this article, unless otherwise stated. 